BULLETIN Bulletin hispanique

HISPANIQUE Université Michel de Montaigne Bordeaux

113-2 | 2011

Varia

\title{
Interacciones de la canción
}

«Del conocimiento de sí mismo», atribuida a fray Luis de León, y tres poemas latinos de Benito Arias Montano

\section{Antonio Dávila Pérez}

\section{(2) OpenEdition}

Journals

Edición electrónica

URL: http://journals.openedition.org/bulletinhispanique/1404

DOI: 10.4000/bulletinhispanique.1404

ISSN: 1775-3821

Editor

Presses universitaires de Bordeaux

Edición impresa

Fecha de publicación: 1 diciembre 2011

Paginación: 527-548

ISBN: 978-2-86781-793-9

ISSN: 0007-4640

\section{Referencia electrónica}

Antonio Dávila Pérez, «Interacciones de la canción », Bulletin hispanique [En línea], 113-2 | 2011,

Publicado el 01 diciembre 2014, consultado el 06 mayo 2019. URL : http://journals.openedition.org/

bulletinhispanique/1404; DOI : 10.4000/bulletinhispanique.1404 


\title{
Interacciones de la canción "Del conocimiento de sí mismo», atribuida a fray Luis de León, y tres poemas latinos de Benito Arias Montano
}

\author{
Antonio Dávila Pérez \\ Universidad de Cádiz - Espagne
}

Cet article met en évidence les coïncidences entre la chanson «Del conocimiento de sí mismo", traditionnellement attribuée à fray Luis de León, et trois poèmes latins de Benito Arias Montano publiés dans les collections Hymni et Secula (Anvers, 1593) et Poemata in quattuor tomos distincta (Anvers, 1589). Nous proposons aussi trois hypothèses sur l'attribution de la composition en espagnol.

Este artículo muestra las coincidencias entre la canción "Del conocimiento de si mismo", tradicionalmente atribuida a fray Luis de León, y tres poemas latinos de Benito Arias Montano publicados en las colecciones Hymni et Secula (Amberes, 1593) $y$ Poemata in quattuor tomos distincta (Amberes, 1589). Proponemos, además, tres hipótesis sobre la atribución de la composición española.

This article shows the coincidences between the song "Del conocimiento de sí mismo", attributed as usual to fra Luis de León, and three poems in Latin by Benito Arias Montano, that were published in the collections Hymni et Secula (Antwerp, 1593) and Poemata in quattuor tomos distincta (Antwerp, 1589). In addition, we propose three hypotheses as to the attribution of the composition in Spanish.

Mots-clés : Arias Montano - Fray Luis de León - Poésie vernaculaire - Poésie néolatine - Renaissance.

Bulletin Hispanique, Tome 113, nº 2 - décembre 2011 - p. 527 à 548. 
$\mathrm{L}$ As conexiones entre la poesía renacentista neolatina y la vernácula se deben a los muchos vínculos de todo tipo, cronológico, geográfico y hasta personal, de sus autores. Benito Arias Montano (ca. 1525-1598) y fray Luis de León (1527-1591) tienen vidas y obras entrelazadas: se educaron con los mismos maestros, se entregaron al estudio de la Biblia como principal ocupación y crearon sus poemas líricos hacia la segunda mitad del siglo XVI. Hay que estar, por tanto, alerta no sólo ante la imitatio que operan los humanistas sobre las fuentes clásicas, bíblicas o patrísticas, sino también ante estos contactos permanentes entre literatura neolatina y vernácula ${ }^{1}$.

Las coincidencias entre Arias Montano y fray Luis van más mucho allá de la creación poética lírica. El papel de Arias Montano como mentor y condiscípulo de fray Luis aflora en distintos ámbitos de la producción y formación del humanista ${ }^{2}$. José María Maestre ha probado de forma fehaciente que la gramática en latín de la lengua italiana compuesta por Montano ${ }^{3}$ estaba dirigida a fray Luis ${ }^{4}$. En el presente artículo intentaré demostrar que existe, cuando menos, una fuerte interacción entre la canción «Del conocimiento de sí mismo", atribuida a fray Luis de León, y tres poemas latinos de Benito Arias Montano.

* El presente trabajo forma parte del proyecto de investigación de la DGICYT FFI200910133 y del Proyecto de Excelencia de la Junta de Andalucía con referencia PAI09HUM-04858. Agradezco al profesor J. M. Maestre Maestre la atenta lectura del original y las sugerencias con las que lo ha enriquecido.

1. Una sucinta bibliografía sobre las relaciones y concomitancias intelectuales de esos personajes debe incluir los trabajos de S. Diego en «Versión métrica del Salterio», Revista Española de Estudios Bíblicos, 25, 1928, 71-77; F. Cantera, "Arias Montano y Fr. Luis de León", Boletin de la Biblioteca de Menéndez Pelayo, 12-4, 1946, p. 299-338; J. López de Toro, "Fray Luis de León y Arias Montano», Revista de Archivos, Bibliotecas y Museos, 61-2, 1955, p. 531-549; J. F. Alcina, «Introducción» a Fray Luis de León. Poesía, Madrid, Cátedra, 1986; y J. F. Domínguez Domínguez, "Carta de Arias Montano a Fray Luis de León. Comentario, edición y traducción", Cuadernos de Pensamiento, 12, 1988, p. 285-312.

2. Ya estudiados por F. Cantera, «Arias Montano y Fray Luis», p. 303 y p. 307.

3. Conservada en dos partes: en el códice K-III-8, ff. [223v]-231 ${ }^{\text {r }}$ de la Real Biblioteca de San Lorenzo de El Escorial; y en el manuscrito 8588 de la Biblioteca Nacional de Madrid, ff. $\left[121^{\mathrm{v}}\right]-152^{\mathrm{r}}$.

4. Cf. J. Ma . Maestre Maestre, «Fray Luis de León, principal destinatario de la gramática italiana en latín de Benito Arias Montano", Silva, 1, 2002, p. 141-156; y J. Mª. Maestre Maestre, «Descubrimiento de la parte perdida de la gramática italiana en latín de Benito Arias Montano", Excerpta Philologica Iosepho Ludouico Pereira Iglesias sacra, 10-12, 2000-2002, p. 319-332. 


\title{
I. LA CANCIÓN «DEL CONOCIMIENTO DE SÍ MISMO» ATRIBUIDA
}

\author{
A FRAY LUIS DE LEÓN
}

El poema «Del conocimiento de sí mismo», que comienza «En el profundo del abismo estaba», es una canción petrarquista de trece estancias de trece versos cada una ${ }^{5}$. Aparece publicada en las principales ediciones de las poesías de fray Luis de León ${ }^{6}$ : la de Francisco Quevedo en 16137, la de Antolín Merino en $1816^{8}$, la de Juan F. Alcina en $1986^{9}$ y las de Oreste Macrí de 1970 y $1982^{10}$.

La mayor parte de los críticos defienden la autoría de fray Luis ${ }^{11}$. Tan sólo la rechaza José Llobera ${ }^{12}$ aduciendo los siguientes argumentos formales: abundancia de prosaísmos; excesivas enumeraciones, tan poco características de fray Luis; acumulación de sustantivos del tipo «la vida, el alma, el cuerpo

5. En cuanto a la transmisión manuscrita, este poema se conserva en la Biblioteca Nacional (Ms. 3782, fo 47v, Ms. 3977, fo 66 y Ms. 4142, fo 46 v.); en la Real Academia de la Historia (Ms. 9-2.079, fo 144 y Ms. 9-2.084, fo 47); en la Biblioteca Universitaria de Oviedo (Ms. 255, fo 106); en la Biblioteca de don Bartolomé March (Ms. 23/4/3, fo 49v); en la Biblioteca de M. Menéndez Pelayo en Santander (Ms. 149, fo 65); y en la Biblioteca de A. Rodríguez Mońino (Cancionero de Jesuitas, fo 139). Estos datos proceden del apartado que dedica J. M. Blecua a los impresos y manuscritos utilizados en su edición Fray Luis de León. Poesía completa, Madrid, Gredos, 1990, p. 97-149.

6. Un recorrido por la transmisión textual de la poesía de fray Luis de León se lee también en la edición de Blecua de Fray Luis de León. Poesía completa, p. 13-26.

7. Obras propias y traducciones latinas, griegas y italianas. Con la parafrasi de algunos salmos y capitulos de Job. Autor el doctíssimo y reverendíssimo padre fray Luis de León, de la gloriosa orden del grande doctor y patriarca San Agustin. Sacadas de la librería de don Manuel Sarmiento de Mendoça, canónigo de la magistral de la Santa Iglesia de Sevilla. Dalas a la impresión don Francisco de Quebedo Villegas, cavallero de la Orden de Santiago..., Madrid, 1631, fo 42.

8. Obras del M. Fr. Luis de León de la orden de San Agustín, reconocidas y cotejadas con varios manuscritos por el P. M. Fr. Antolin Merino de la misma orden, 6 vols., Madrid, 1804-1816, vol. VI, p. 89 (Apéndice).

9. Alcina, Fray Luis de León, p. 199-203.

10. La poesía de Fray Luis de León, introducción, edición crítica y comentario de Oreste Macrí, Salamanca, Anaya, 1970, p. 281 (Apéndice); y Fray Luis de León. Poesías. Estudio, texto crítico, bibliografía y comentario de Oreste Macrí, Barcelona, Editorial Crítica, 1982, p. 261 (Apéndice).

11. Cf. Macrí, La poesía de Fray Luis de León, p. 378, quien anota que esta canción ha sido alabada por Menéndez Pelayo como «Dignísima de Fray Luis, aunque algo desigual»; que, según Arjona, Fray Luis aquí "sigue el estilo italiano, pero sin detenerse en conceptos poco sólidos»; y que Coster, Aubrey Bell, Entwistle, Vossler y la mayor parte de los críticos tradicionales también defienden la autoría del agustino.

12. J. Llobera, Obras poéticas de fray Luis de León, 2 vols., Cuenca, 1932-1933, vol. I, 373-378. 
y el sentido» (v. 5); repetición y el juego de palabras, como «y en fin mi ser no ser entonces era» (v. 6); empleo de metáforas carentes de naturalidad («aquel rocío soberano / que obraba en ella el celestial verano», vv. 88-89); abundancia de versos sáficos y frecuencia de acentos en la tercera sílaba de los versos endecasílabos. J. M. Blecua suscribe la opinión de Llobera y deja este poema fuera de su edición de la poesía de fray Luis ${ }^{13}$.

Macrí califica la canción presuntamente luisiana como un «desacostumbrado documento autobiográfico». Expongamos para empezar su contenido. El poeta se repliega hacía sí mismo para indagar las razones de la enfermedad de su alma: primero, el pecado original; tras el bautismo, el alma vuelve a caer rendida a los vicios y pasiones. El reconocimiento de la propia vileza lleva al poeta a realizar un ejercicio de penitencia, una lucha contra sus pasiones, y, en último término, a dirigir su oración a la misericordia divina. En el poema se distinguen con claridad las bases de la poética y retórica bíblica que enlazaron las obras de Arias Montano y fray Luis: el tratamiento en exclusividad del tema religioso, la misión doctrinal, y una marcada religiosidad interior. Es cierto que domina una primera persona central, pero la presencia del poeta es más bien un artificio retórico para reforzar la función doctrinal del poema.

\section{TRES POEMAS LATINOS DE ARIAS MONTANO EN LA VÍA ASCÉTICA DEL RECOGIMIENTO}

Pues bien, en la producción lírica de Arias Montano hallamos tres poemas latinos de introspección religiosa que considero relacionados con la canción "Del conocimiento de sí mismo»: sus títulos son «Agnitio», «Votum poenitentiae» y "Paraenesis ad mentem propriam». Los dos primeros están incluidos en la colección lírica titulada Hymni et Secula (Amberes, 1593) ${ }^{14}$. $\mathrm{La}$ "Paraenesis ad mentem propriam» cierra el libro Odae variae. Quarum aliae desumptae ex Commentariis in minores prophetas, aliae nunquam antea editae, título incluido en el primer volumen de la colección lírica Poemata in quattuor tomos distincta (Amberes, 1589), p. 91-142 ${ }^{15}$. En estos poemas, Arias Montano recorre en primera persona los tres pasos básicos, los tres

13. Cf. Blecua, Fray Luis de León, p. 36-37.

14. Existen dos estudios parciales sobre esta colección: G. Marín Mellado, «El libro segundo de los Secula de Benito Arias Montano" (Tesis de Licenciatura inédita, Universidad de Cádiz, 1997); y A. Dávila Pérez, «Benito Arias Montano. Seculorum liber V» (Tesis de Licenciatura inédita, Universidad de Cádiz, 1997).

15. Contamos con una excelente edición moderna de esta colección poética realizada por Guadalupe Marín Mellado, «Las Odae variae de Benito Arias Montano. Introducción, edición crítica, traducción anotada e índices» (Tesis Doctoral inédita, Universidad de Cádiz, 1999). 
grados de la vía del recogimiento, la corriente mística más practicada en la espiritualidad española del siglo XVI: autoconocimiento, penitencia y oración $^{16}$.

En la "Agnitio», de 45 dísticos elegíacos, poema octavo del libro quinto de los Secula, Montano realiza una revisión de sus vicios y pasiones, en un necesario acto de vuelta hacia sí mismo y autoconocimiento. El conocerse a sí mismo, la agnitio, permite al hombre descubrir la raíz de su pecado: la culpa de los primeros padres ha sido heredada a sus descendientes; su corazón está infestado de pasiones que le impiden ejercer la verdadera caridad cristiana. La estructura de este poema latino puede esquematizarse así:

vv. 1-20: introducción: la ley revela la enfermedad del alma humana;

vv. 20-68: autoconocimiento: recapitulación de vicios y pasiones del alma como consecuencia del pecado original;

vv. 72-84: Nostalgia de la simplicidad anterior al pecado de los primeros padres;

vv. 85-89: Conclusión: el poeta se pregunta quién va a poder curar su alma enferma.

En el «Votum Poenitentiae», compuesto en 78 dísticos elegíacos, noveno poema del libro quinto de los Siglos, concentra el humanista sus esfuerzos por mostrar al lector una piedad sincera a partir de la reflexión sobre la Ley, analizando con la usual primera persona la naturaleza religiosa e intenciones del alma humana. Tres son los pilares básicos de la bondad cristiana: Temor a Dios, Penitencia y Amor ${ }^{17}$. Tras el necesario proceso de recogimiento y autoconocimiento planteado en "Agnitio" se impone un votum poenitentiae, un ejercicio completo de penitencia, que es entendida por Montano como la lucha que el hombre hace contra sus pasiones ${ }^{18}$. Este largo poema queda estructurado de la siguiente manera:

vv. 1-6: Exordio: el poeta implora ayuda celestial para sofocar las llamas de sus pasiones;

16. Un análisis exhaustivo de las corrientes espirituales del Renacimiento español se encuentra en el clásico trabajo de M. Andrés, La teología española del siglo XVI, 2 vols., Madrid, BAC, 1976-1977, vol. II, p. 107-295. Para la espiritualidad del recogimiento véase la monografía del mismo autor titulada Los recogidos. Nueva visión de la mistica española (1500-1700), Madrid, Fundación Universitaria Española, 1976.

17. Así lo expone Arias Montano en su Dictatum Christianum siue comunes et aptae discipulorum Christi omnium partes, Amberes, 1575, p. 57-58.

18. Cf. Arias Montano, Dictatum Christianum, p. 75: "Hanc igitur poenitentiam uirtutem diuinae sapientiae ratio sacris libris exposita in eo consistere maxime docet, ut homo cupiditatibus suis bellum indicat et inferat, fortissimeque se ipsum uincat, atque a mundanis et carnalibus actionibus operibusque contineat, et iis quae a Deo praecipiuntur, commendatur et probantur studiis et actionibus, curam operamque adhibeat». 
vv. 7-59: Primer nivel hacia la anhelada perfección espiritual: la corrección exterior no basta, pues se debe realizar un ejercicio de limpieza interior de las propias pasiones;

vv. 60-82: Segundo nivel: la ley de Dios enseńa que el alma, de naturaleza superior a los seres terrenales, debe liberarse del pecado para parecerse a Dios;

vv. 83-94: Tercer nivel: la ley muestra el camino, pero es cada hombre quien, tras el necesario autoconocimiento, debe mantener una dura pugna personal contra sus pasiones;

vv. 95-140: Penitencia: la necesaria lucha del hombre contra sus pasiones para acercar el alma a Dios;

vv. 141-156: Oración: Dios es la única medicina del alma enferma.

La transición entre los poemas octavo y noveno del libro quinto de los Siglos es tan sutil que puede plantearse la idea de que «Agnitio» y el «Votum poenitentiae» forman un continuum, estructurado en los tres pasos básicos de la vía ascética del recogimiento: autoconocimiento, penitencia y oración. Existen claros elementos que avalan esta idea de unidad formal y de fondo de los dos poemas: "Agnitio» comienza manifestando la necesidad de buscar la medicina del alma, imagen que tiene su eco en los últimos versos del «Votum poenitentiae», produciendo una cerrada composición en anillo, donde el poeta considera a Dios, en su oración final, el único que puede sanarlo de su enfermedad. Asimismo, el final de "Agnitio» enlaza de forma perfecta con el principio de "Votum poenitentiae» por el tono afectivo de interrogaciones retóricas dirigidas de forma indirecta a Dios:

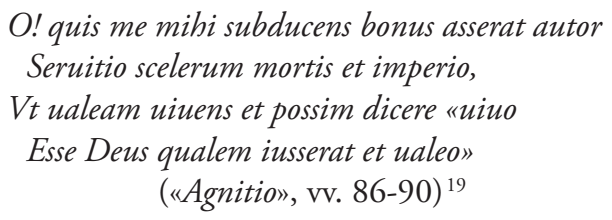

Quis superum undantes lachrymarum det mihi riuos

Perpetuo e moestis ducere luminibus?

Quis nimium ardenti renouet suspiria cordi,

Temperet ut flammas uentus et unda meas?

(«Votum poenitentiae», vv. 1-4) $)^{20}$

19. «¡Oh! ¿Qué buen defensor me va a salvar liberándome / de la esclavitud de mis sacrilegios y del poder de la muerte, / para que goce de salud en vida y pueda decir "vivo / como Dios había ordenado que fuera y gozo de salud"?».

20. «¿Quién de los de arriba me concederá hacer brotar arrebatadas fuentes / de lágrimas 
En la «Paraenesis ad mentem propriam», de 57 estrofas alcaicas, Montano dirige un discurso persuasivo a su propia alma planteándole como finalidad última la vida contemplativa, a la que solo se puede acceder mediante la lucha ascética de los vicios, la penitencia y la oración.

G. Marín propone la siguiente estructura del poema ${ }^{21}$ : «vv. 1-20: exhortación a su alma para que salga de la pereza y el embotamiento y, en razón de su naturaleza divina, busque y celebre a Dios; vv. 21-36: ascetismo: el alma debe arrojar lejos de sí el fardo de los vicios y placeres mundanos para entregarse al fin antes anunciado; vv. 37-80: primer argumento para que cumpla lo aconsejado: la debilidad de la carne y el antagonismo radical entre carne y espíritu; vv. 81-108: segundo argumento: fugacidad de la vida y poder destructor de la muerte; vv. 109-120: tercer argumento: aunque el alma sea inmortal, tras la muerte llega inexorable la retribución divina que premia a los justos y castiga a los pecadores; vv. 121-140: por todo esto el alma debe concentrarse en adorar a Dios y en practicar virtudes; vv. 141160: reiteración del segundo argumento: la muerte llega de forma súbita, no debe coger el alma desprevenida y con sus obligaciones abandonadas; vv. 161-180: repetición con variación del tercer argumento: la posibilidad de arrepentimiento tiene un límite, en el futuro aguarda la recompensa o el castigo; vv. 181-208: más advertencias: debe dejarse guiar por la prudencia y seguir las leyes de Dios; vv. 209-224: nueva imagen del juicio final y de la dicha que le aguarda si sigue los preceptos que da el poeta; vv. 225-228: conclusión: última exhortación a consagrarse a Dios».

La espiritualidad del recogimiento, con distintas vías de autoconocimiento, y la penitencia y oración, son la materia básica de una oda, compuesta también íntegramente a partir de la interpretación de las sagradas letras, que a todas luces coincide en su planteamiento, ideas y objetivos con los dos poemas de Hymni et Secula arriba analizados. Es más: parece que esta oda fue compuesta por Montano para incluirla en sus Hymni et Secula, pues en el manuscrito 155 de la Biblioteca Nacional (folios 143r-148r), que contiene la mayor parte de los poemas de Hymni et Secula en forma de borrador o copia, la oda aparece bajo el lema Hymni.

Queda claro, pues, que el planteamiento temático de la canción castellana atribuida a fray Luis y el de estos poemas latinos montanianos es idéntico. Pero se registran muchas más coincidencias de forma y fondo que demuestran, cuando menos, una indudable conexión entre ellos.

para siempre de mis apenados ojos? / ¿Quién va a renovar los sollozos de mi corazón en demasía hervoroso, / para que este viento y agua sofoquen mis llamas?».

21. Marín Mellado, «Las Odae variae de Benito Arias Montano», p. 122. 


\section{CoINCIDENCIAS DE LOS POEMAS LATINOS DE ARIAS MONTANO CON LA CANCIÓN «DEL CONOCIMIENTO DE SÍ MISMO»}

III.1 En primer lugar, el mismo título de la oda "Del conocimiento de sí mismo" remite a uno de los poemas montanianos, "Agnitio", que bien podría traducirse por "Conocimiento de sí mismo", porque conocerse a sí mismo es re-conocerse. Pero por si queda alguna duda sobre la equivalencia de título entre el poema neolatino y la canción castellana, Arias escribe en los versos 19-20 que tras la entrega de la Ley, primera alianza de Dios con su pueblo,

\section{Haec me diuini deduxit luminis umbra quod satis est ut sim cognitus ipse mibi,}

que traducimos como «Ésta me sacó de la sombra, pues hay en ella luz divina suficiente para conocerme a mí mismo». El principio nosce te ipsum, de raigambre socrático-platónica, es entendido como el fundamento de todos los bienes: "Porque, al revés, en el desconocerse y en el estimarse en lo que no es, está el error de la vida. Y como no entra el sol adonde se cierran las puertas, ansí no entra Dios en el alma que no se conoce; porque las puertas que la cierran es la estimación vana de sí y el juicio falso de su virtud y fuerza» (fray Luis de León, Exposición del Libro de Job, cap. XL, 1) ${ }^{22}$.

III.2 La reflexión interior del poema castellano sobre la enfermedad del alma humana se desenvuelve en dos etapas: Antiguo Testamento (pecado original), y la entrega a los vicios posterior al bautismo (Nuevo Testamento), según la siguiente estructura: vv. 1-13: introducción: el no ser del hombre antes de los tiempos; vv. 14-39: El alma humana en el Antiguo Testamento: génesis y primera culpa de los padres; vv. 40-65: El alma humana tras el Nuevo Testamento: Jesucristo, segunda alianza y bautismo; vv. 66-130: autoconocimiento y penitencia; enfermedad del alma humana y lucha contra las pasiones; vv. 131-156: oración: exhortación a la bondad y misericordia divinas; vv. 157-169: conclusión: curación por parte de Dios.

Hay, por tanto, una presencia explícita de la cronología bíblica en la canción «Del conocimiento de sí mismo». Y la prueba léxica que mejor avala esta idea se encuentra en los primeros versos. El poeta se presenta como la nada, el no ser antes de los tiempos, hasta que anuncia su propia creación con estas palabras:

22. Véase el artículo de R. Cao Martínez titulado «El conocimiento de sí en fray Luis de León», Revista Agustiniana, 39-118, 1998, p. 85-128. 
Estando, pues, en tal tiniebla oscura, volviendo ya con curso presuroso el sexto siglo el estrellado cielo, miró el gran Padre, Dios de la natura, y viome en sí benigno y amoroso, y sacóme a la luz de aqueste suelo,

(vv. 14-19)

A una parte de la crítica le ha costado interpretar el sintagma «sexto siglo». Según Macrí, con la palabra «siglo» alude fray Luis al siglo en que nació, ya prolongado por el cielo en 28 ańos. Coster lee «sexto signo», interpretando el sexto signo del Zodíaco: en el año antiguo, la Virgen, mes de septiembre, en que nació fray Luis; los Gemelos en el año cristiano, mes de junio, en que él mismo fue concebido.

Sin perjuicio de las fuentes antiguas que puedan alegarse ${ }^{23}$, un simple acercamiento a la obra de Arias Montano ayuda a resolver la crítica textual y la hermenéutica del sintagma "sexto siglo». Recordemos que los poemas "Agnitio» y "Votum Poenitentiae» se incluyen en la colección Hymni et Secula (Himnos y siglos), que es un recorrido poético por los tiempos bíblicos. Y, además, en sus comentarios a la Biblia Montano ofrece una pausada explicación de la división de los tiempos en seis siglos o períodos:

Omnis autem haec temporis ratio, ab ipso mundi initio ad ea usque tempora quibus hominum salus in Christo perfecta est, a sanctis uatibus atque ab ipsis Apostolis seculorum nomine significatur. In qua quidem diuinae sapientiae, misericordiae ac $\pi \alpha v \tau o \delta v v \alpha \mu i \alpha s$ maxima argumenta sunt explicata. Fluxerunt enim totis illis seculis a promissione primis parentibus facta, quam nos apud Euangelistas

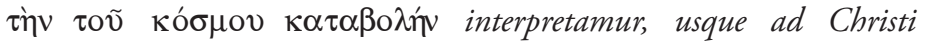
aduentum, qui fuit temporum plenitudo, secula sex quae propie GHOLAMIM uocantur. Quorum primum ab Adam usque ad diluuium recensetur: secundum a diluuio (cum salutis foedus cum Noё fuit instauratum) usque ad Abraham iuxta diuisas uictimas dormientem: tertium ab Abraham usque ad Iacob, cui apud Luzam pernoctanti sacrosanctum mysterium sub imagine scalae fuit ostensum: quartum a Iacob usque ad legem in Sina monte promulgatam et foedus cum omni populo sancitum: quintum a lege usque ad regnum Dauidis, cui singulari oraculo significatum est, fori ut mundi redemptor ab ipso genus duceret. Hinc uero usque ad Christum sextum seculum definimus.

23. Isidoro, Etym., V, 38,6, quien define sexto siglo como la sexta edad del mundo, desde la llegada de Cristo «usque quo mundus iste finiatum. 
Is enim rerum omnium plenitudo fuit; et ea quidem lux quae superiores illas umbras consecuta est. Atque ultra hanc aetatem sunt saeculorum fines ac noui mundi apparatio et adquisitio regni illius caelestis, quod quidem per Christi mortem atque eiusdem resurrectionem, ascensum in caelos et promissionis suae confrrmationem Spiritus Sancti inmissione insignitam, nobis comparatum est ${ }^{24}$.

Así pues, en el poema castellano se hace una clara referencia a las seis edades (o secula) que transcurren desde la creación, primer siglo, hasta la llegada de Jesucristo, sexto y último período. Con todo esto queremos demostrar que no sólo hay plena coincidencia temática entre la canción atribuida a fray Luis y los poemas latinos de Montano, sino que también se produce una combinación idéntica de ascética del recogimiento y cronología bíblica.

III.3 El devenir del alma humana contado en el poema castellano se apoya en dos imágenes, dos metáforas que recorren el poema de principio a fin. En primer lugar, el contraste tinieblas/luz distingue el tiempo de la ignorancia del tiempo del conocimiento. Se trata de una imagen que fray Luis desarrolló de forma prolija en su Panegyricus Diuo Augusto Dictus partiendo del Eclesiástico, 27,12: "Vir intelligens in sapientia manet sicut Sol; nam stultus sicut luna mutatun ${ }^{25}$.

Comparemos los versos castellanos:

Estando, pues, en tal tiniebla oscura, volviendo ya con curso presuroso el sexto siglo el estrellado cielo, miró el gran Padre, Dios de la natura, y viome en sí benigno y amoroso, y sacóme a la luz de aqueste suelo,

(«Del conocimiento de sí mismo», vv. 14-19)

24. La primera vez que podemos leer este texto en la obra de Montano es en Daniel siue de saeculis codex integer, en Biblia Sacra, Hebraice, Chaldaice, Graece et Latine, Antuerpiae, Chr. Plantinus excud., 1569-1572, vol. 8. El Daniel... se reeditó en varias ocasiones: Benedicti Ariae Montani Hispalensis volumen de Saeculis, incluido al final -p. 520-536- de la obra de Veldio Daniel Propheta commentariis pro concione explicatus, Amberes, 1576; también se puede leer en los Antiquitatum Iudaicarum libri IX, Leiden, 1593, p. 187; la última edición que conozco va incluida también en la obra de Veldio Commentaria et Conciones in Danielem Prophetam. Cum Chronologia ad intelligenda Ieremiae, Ezequielis et Danielis uaticinia et uolumine de saeculis Ben. Ariae Montani, Amberes, 1602, p. 520-536.

25. Cf. Cao Martínez, «El conocimiento de sí en fray Luis de León», p. 93-98. 
Sufrióme entonces tu piedad divina y sacóme de aquel hediondo cieno, do, sin sentir aún el hedor, estaba con falsa paz el ánima mezquina, juzgando por tan rico y tan sereno el miserable estado que gozaba, que sólo deseaba perpetuo aquel contento; pero sopló a deshora un manso viento del Espíritu eterno, y enviando un aire dulce al alma, fue llevando la espesa niebla que la luz cubría, dándole un claro y muy sereno día.

(«Del conocimiento de sí mismo», vv. 105-117)

con los siguientes de Montano:

Discussis tenebris, proprium cognoscere morbum et sentire malum lex mihi sancta dedit

Haec me diuini deduxit luminis umbra Quod satis est ut cognitus ipse mibi. («Agnitio», vv. 16-20) ${ }^{26}$

Las coincidencias no se limitan al nivel de las res, sino que alcanzan también los uerba. El ablativo absoluto "Discussis tenebris» se corresponde con «Estando, pues, en tal tiniebla oscura» (v. 14) y «fue llevando / la espesa niebla». El verso montaniano "Haec me diuini deduxit luminis umbra» encuentra una aceptable traducción en el verso castellano («y sacóme a la luz de aqueste suelo»).

Pero es que, volviendo de nuevo al planteamiento metafórico oscuridad/ luz, este contraste es también leitmotiv de los Hymni et Secula de Montano, cuyo último libro se titula Oriens, en referencia a Jesucristo que es como un sol que nace.

La segunda metáfora que adorna el poema atribuido a fray Luis presenta a Jesucristo como médico y al pecador como enfermo, imagen que es antigua y ha sido usada también por fray Luis en sus poesías originales. La idea se relaciona con San Ambrosio: "omnia Christus est nobis: medicus, fons,

26. «Se disiparon las tinieblas y la ley santa me concedió conocer / mi propia enfermedad y darme cuenta del mal. / Ésta me sacó de la sombra, pues hay en ella luz divina / suficiente para conocerme a mí mismo». 
iustitia, ...» ${ }^{27}$. Fray Luis presenta también a Jesús como salud en Los nombres de Cristo (p. 759-761), y en su oda VI, vv. 89-90:

\author{
Preséntote un sujeto \\ tan mortalmente herido cual conviene, \\ do un médico perfecto \\ de cuanto saber tiene \\ dé muestra, que por siglos mil resuene.
}

Lo que sí debe destacarse aquí es la relevancia estructural de esta metáfora en el poema castellano, pues sirve para abrirlo y cerrarlo en una perfecta composición en anillo. En la primera parte de la canción castellana se refleja el estado de enfermedad que acarreó al alma humana el pecado original:

¡Oh culpa amarga, y cuánto bien quitaste al alma mía! ¡Cuánto mal hiciste! Luego que fue criada y junto infusa, tú de gracia y justicia la privaste, y al mismo Dios contraria la pusiste; ciega, enemiga, sin favor, confusa, por ti siempre rehúsa el bien, y la molesta la virtud, y a los vicios está presta; por ti la fiera muerte ensangrentada por ti toda miseria tuvo entrada, hambre, dolor, gemido, fuego, invierno, pobreza, enfermedad, pecado, infierno.

(«Del conocimiento de sí mismo», vv. 27-39)

Esta misma imagen, presentando ahora a Dios como médico, cierra la estancia final de la canción:

Apenas hube dicho aquesto, cuando con los brazos abiertos me levanta y me otorga su amor, su gracia y vida, y a mis males y llagas aplicando la medicina soberana y santa, a tal enfermedad constituida, me deja sin herida, de todo punto sano, pero con las heridas del tirano 
hábito, que iba ya en naturaleza volviéndose, y con una tal flaqueza, que, aunque sané del mal y su accidente, diez años ha que soy convaleciente.

(«Del conocimiento de sí mismo», vv. 157-169)

Pues bien, los poemas de Montano "Agnitio» y «Votum Poenitentiae» quedan enmarcados por este mismo planteamiento metafórico, generando una idéntica estructura anular. Una vez más, coincidencia exacta de forma y fondo. Así en "Agnitio» Arias dedica los dieciocho primeros versos a manifestar la conciencia que ha adquirido de su propia enfermedad y la necesidad de buscar una medicina espiritual:

Non mihi in alterius culpam iam crimina ut uni

Criminis experti quaerere iure licet.

Non iam cura prior quid quisquam sentiat aut quo

Cogitet experiens uiuere consilio.

Maius constat opus, restat sudorque laborque,

Quarenda est morbis si medicina meis.

Hactenus aegrotare omnes certe ipse putabam

Dissimiles nostri moribus ingenii;

Et mibi praecipue sanusque ualensque uidebar,

Plaudebam inuentis unus et ipse meis.

Solos qui mecum sentirent, rebar amicos

Inuidus aduersis legibus ac placitis.

Inde odia et rixas inimicaque bella querebar

Ingenti alterius crimine lata mihi,

Turbare et nostram delicta aliena quietem,

Iusta uideretur cum mihi causa mea.

Discussis tenebris, proprium cognoscere morbum

Et sentire malum lex mihi sancta dedit.

("Agnitio», vv. 1-18) $)^{28}$

28. «No me está permitido a mí, así como a alguien libre de pecado, / reclamar acusaciones contra la culpa del prójimo. / No importa ahora sobre todo cuáles son los sentimientos de nadie / o con qué parecer se ha propuesto vivir activamente. Queda una tarea mayor, restan sudor y trabajo, / si hay que buscar la medicina de mis propias enfermedades. / Hasta ahora tenía por seguro que estaban enfermos todos / los que tenían costumbres distintas a las mías; / y me parecía que yo estaba especialmente sano y fuerte, / y yo era el único que aprobaba mis reglas. / Sólo consideraba amigos a los que compartían mi parecer, / enemigo como era de leyes y pareceres contrarios. / Por eso me quejaba de los odios, las riñas y las guerras enemigas / que soportaba por el pecado de otra procedencia, / y de que las faltas ajenas perturbaran mi tranquilidad / pues me parecía justa mi causa. / Se disiparon las tinieblas y la ley santa me concedió conocer / mi propia enfermedad y darme cuenta del mal.» 
Y esa medicina sólo la puede proporcionar la misericordia de Dios, a la que apela el poeta neolatino en los últimos versos del «Votum Poenitentiae»:

Ergo quid quaeram aut repetam nisi te, Deus, unum?

Vnicus aegrotum me recreare potes;

Vnicus et rerum uita es et luminis autor,

Tu superum uita es, tu quoque lux hominum.

$O$, miserere operis precor (o!) cari tibi quondam

Non solito placidum uertere propositum.

Iamque hominem ipse tui mortalem unius egentem

Visere curandum suscipere atque uelis.

Me dum restituis uitae, me dum tibi seruum

Asseris, ad laudes consulis ipse tuas.

(«Votum poenitentiae», vv. 141-150) ${ }^{29}$

Las imágenes de Jesucristo como sol de justicia y, al mismo tiempo, fuente de salud se combinan en la siguiente estrofa montaniana:

Tunc sol tibi, o mens, iustitiae intima

Virtute siste clarus et efficax,

Cuius salubri fota uines

Praesidio medicisque pennis.

("Paraenesis ad mentem propriam», vv. 221-224) ${ }^{30}$

III.4 Gusto por el registro dramático y la ficción dialógica. La estructura comunicacional es una característica conocida de las odas horacianas. En las tres últimas estancias de la canción castellana el poeta se convierte en emisor y se dirige a Dios, receptor que se imagina presente, para formular su oración:

Padre piadoso, dije, Padre santo, benigno Padre, Padre de consuelo, perdonad, Padre, aqueste atrevimiento; a vos vengo, aunque siento, de mí mismo corrido, que no merezco ser de vos oído; mas mirad las heridas que me han hecho mis pecados, cuán roto y cuán deshecho

29. Véase la traducción en nota 31.

30. «Entonces se detendrá para ti, alma, / el sol de justicia, brillante y poderoso / en su profunda virtud, y vivirás al abrigo / de su baluarte salutífero y sus alas curativas». Traducción de G. Marín, «Odae uariae», p. 136. 


\section{LA CANCIÓN «DEL CONOCIMIENTO DE SÍ MISMO»}

me tienen, y cuán pobre y miserable, ciego, leproso, enfermo, lamentable.

Mostrad vuestras entrańas amorosas en recebirme agora y perdonarme, pues es, benigno Dios, tan propio vuestro tener piedad de todas vuestras cosas; y si os place, Señor, de castigarme, no me entreguéis al enemigo nuestro; a diestro y a siniestro tomad vos la venganza, herid en mí con fuego, azote y lanza; cortad, quemad, romped; sin duelo alguno atormentad mis miembros de uno a uno, con que, después de aqueste tal castigo, volváis a ser mi Dios, mi buen amigo.

(«Del conocimiento de sí mismo», vv. 134-156)

Arias Montano culmina su poema «Votum Poenitentiae» con una similar imprecación a la divinidad.

Ergo quid quaeram aut repetam nisi te, Deus, unum?

Vnicus aegrotum me recreare potes;

Vnicus et rerum uita es et luminis autor,

Tu superum uita es, tu quoque lux hominum.

$O$, miserere operis precor (o!') cari tibi quondam

Non solito placidum uertere propositum.

Iamque hominem ipse tui mortalem unius egentem

Visere curandum suscipere atque uelis.

Me dum restituis uitae, me dum tibi seruum

Asseris, ad laudes consulis ipse tuas.

Nam quanquam Deus inmensus sapiensque potensque et Vatum carminibus diceris esse bonus.

Fama ait ulterius longe te audire benignum,

Inde tuis primum laudibus esse decus.

Ergo bone, o, tua, quam fallax seduxerat hostis,

Se tibi reddendam poscit imago, veni!

$$
\text { («Votum poenitentiae», vv. 141-156) }{ }^{31}
$$

31. «Así que ¿para qué buscar o requerir a alguien que no seas solo tú, Dios? / Tú eres el único que puedes restablecerme a mí, enfermo; / únicamente tú eres la vida de las cosas y el autor de la luz, / tú eres la vida de los de arriba, tú también la luz de los hombres. / ¡Oh! Compadécete, te lo ruego, de una obra en otro tiempo querida para ti, / que no sueles cambiar tu apacible designio. / Y ojalá ahora a este hombre mortal que sólo te necesita a ti / quieras recibirlo y examinarlo para tu curación. / Mientras me restituyes a la vida, mientras 
III.5 Afectivismo. En el camino hacia la contemplación de Dios es necesario que el alma se entregue a la oración afectiva, derramando llanto sincero de arrepentimiento. La canción castellana presenta al poeta temeroso, humillado y bañado en lágrimas:

[...] que quedando confuso y temeroso, temblando estaba sin hallar reposo.

Ya que, en mí vuelto, sosegué algún tanto, en lágrimas bañando el pecho y el suelo, y con suspiros abrasando el viento:

(«Del conocimiento de sí mismo», vv. 131-133)

Lágrimas, suspiros y temor que inundan también los dos primeros dísticos del «Votum poenitentiae» y las estrofas alcaicas de la «Paraenesis ad mentem propriam».

Quis superum undantes lachrymarum det mibi riuos

Perpetuo e moestis ducere luminibus?

Quis nimium ardenti renouet suspiria cordi,

Temperet ut flammas uentus et unda meas?

(«Votum poenitentiae», vv. 1-4) ${ }^{32}$

Hunc tu dicatae laudis amabili,

Hunc quaere grati munere carminis,

Hunc prona procumbens adora,

Hunc genibus tremebunda flexis,

Huic et supinas tende manus neque

Parcas tepentes ducere riuulos,

Quos supplicis de rore uultus

Fundat honor timor atque castus.

(«Paraenesis ad mentem propriam», vv. 125-132) ${ }^{33}$

me conviertes en tu siervo, / tú mismo velas por tus alabanzas. / Pues aunque eres Dios inmenso, sabio y poderoso, / también se te llama bondadoso en los versos de los profetas. I La fama dice hasta bien lejos que tú escuchas con bondad, / y que de ahí viene la primera gloria de tus alabanzas. / Así que ¡oh -pues ya tu imagen, que un engañoso enemigo había seducido, / pide reflejarse en ti- ven bondadoso!».

32. «¿Quién de los de arriba me concederá hacer brotar arrebatadas fuentes / de lágrimas para siempre de mis apenados ojos? / ¿Quién va a renovar los sollozos de mi corazón en demasía hervoroso, / para que este viento y agua sofoquen mis llamas?».

33. «Búscalo con la estimable ofrenda de tu consagrada / alabanza, búscalo con tu agradable canto, / inclínate y ríndele adoración / de rodillas y llena de temor, / levanta hacia él tus manos / y da rienda suelta a los cálidos arroyos / que del manantial de un rostro suplicante / sustenta el honor y el casto temor;». Traducción de G. Marín, «Odae uariae», p. 130. 
III.6 En la composición castellana se leen llamativas repeticiones y juegos de palabras del tipo "y en fin, mi ser no ser entonces era» (v. 6), «que con su muerte a nuestra muerte / mató» (vv. 48-49), figura a la que también recurre con frecuencia Montano en sus poemas latinos en versos como: «Ludimus inque uices et rapio et rapior» ("Agnitio», v. 44), «Vt ualeam uiuens et possim dicere "uiuo, / Esse Deus qualem iusserat et ualeo" (Agnitio, vv. 89-90), "Sic uera effigies exemplar prospicit unum, / sic propriam exemplar conspicit effigiem» («Votum poenitentiae», vv. 75-76); «Laedere me miserum potui potuique perire : / Vt perii, saluum reddere me haud ualeo» («Votum poenitentiae», vv. 75-76). Fray José de Sigüenza recurre también con frecuencia a esta figura en la traducción castellana en tercetos encadenados que realizó del «Votum poenitentiae» ${ }^{34}$, que por éste y otros rasgos formales se acerca al estilo de la canción «Del conocimiento de sí mismo"; compárense, por ejemplo, las siguientes repeticiones con las de la canción atribuida a fray Luis: "confiesso, y confessarme agora quiero» v. 10; «Jamás probó mi gusto cosa amarga / libre en dañar a quien dañar no supo / sin ser cargado, dar a sentir carga».

III.7 Por último, la canción castellana adolece, según Llobera, de largas enumeraciones impropias de fray Luis. Y precisamente, en los poemas latinos de Montano se leen también extensas series enumerativas, que, en algunos casos, coinciden exactamente con el contenido de las del poema castellano. En los dos fragmentos que se leen a continuación, los poetas, castellano y latino, se entregan a una acumulación de sustantivos, que, además, incide en el mismo contenido: los males que sufre el alma tras el pecado original. De nuevo, coincidencia de forma y fondo:

por ti la fiera muerte ensangrentada, por ti toda miseria tuvo entrada, hambre, dolor, gemido, fuego, invierno, pobreza, enfermedad, pecado, infierno.

(«Del conocimiento de sí mismo», vv. 36-39)

Hinc generis pudor et hinc uitae taedia, magnis

Anxietas cincta et sollicitudinibus;

Nam uideo mihi nata intus mala semina belli,

Ipse hostem tacito pectore porto meum :

At miser ipse mihi insidias fraudemque dolumque

Et ferrum et flammas et mala multa paro.

(«Agnitio», vv. 25-30) ${ }^{35}$

34. Conservada en El Escorial en el manuscrito 22-I-9, fol. 216-226".

35. «De ahí viene la vergüenza de mi linaje y de ahí el hastío de vivir, / y esa angustia 
En otra ocasión se enumeran las partes del cuerpo y del alma :

la vida, el alma, el cuerpo y el sentido

(«Del conocimiento de sí mismo», v. 5)

Membra, manus, oculos, quod uulgus fallere possit, spectatum, oblato tempore dissimulo.

(«Votum poenitentiae», vv. 21-22) ${ }^{36}$

Y, finalmente, también registramos paralelas acumulaciones de adjetivos:

Luego que fue criada y junto infusa, tú de gracia y justicia la privaste, y al mismo Dios contraria la pusiste; ciega, enemiga, sin favor, confusa,

(«Del conocimiento de sí mismo», vv. 29-32)

\section{Dum lateo, turpis nequamque et nudus oberro,}

Cultus et in claro lumine conspicior.

(«Votum poenitentiae», vv. 27-28) ${ }^{37}$

\section{EN TORNO A LA ATRIBUCIÓN DE LA CANCIÓN «DEL CONOCIMIENTO DE SÍ MISMO»}

El gran parecido del estro poético de Montano y León ha provocado ya atribuciones de poesías castellanas de fray Luis a Montano. Marcelino Menéndez Pelayo aprecia el estilo de Montano en las liras «De la hermosura exterior de Nuestra Señora» ${ }^{38}$, oda atribuida a fray Luis por Antolín Merino

ceñida de grandes preocupaciones; / pues veo que ha nacido dentro la funesta semilla de la guerra, / yo mismo llevo a mi enemigo en mi callado pecho. / Y, desgraciado, preparo contra mí emboscadas, engaños, trampas, / espadas, llamas y muchas desgracias».

36. «Gestos, manos, ojos, lo que pueda engañar al vulgo / a simple vista, lo finjo cuando se presenta la ocasión».

37. «Mientras estoy oculto, ando indecente, perverso, desnudo / y se me ve bien ataviado a la clara luz».

38. M. Menéndez Pelayo, Bibliografía hispano-latina clásica, Madrid, 1951, VI, 307. En esta misma línea están también B. Rekers, Arias Montano, Madrid, 1973, p. 229; Cristóbal Cuevas, Fray Luis de León y la escuela salmantina, Madrid, 1982, pp. 144-148, y Gaspar Morocho Gayo en "Avance de datos para un inventario de las obras y escritos de Arias Montano", La Ciudad de Dios, 211-1, 1998, p. 179-275 (p. 257). También replantean la atribución de este poema a fray Luis L. Gómez Canseco y V. Núnez Rivera en Arias Montano 
en su edición de $1816^{39}$. Es posible, dice, que fuera obra del seguidor de fray Luis autor de "Cuando la noche obscura», el cual se habría propuesto reproducir el regalado estilo de Arias en su paráfrasis castellana del Cantar de los Cantares, "pero fuerza sería entonces confesar que lo alcanzó de tal manera, que no hay medio de distinguir los versos del imitador de los de su modelo. Esto, y el tropezar con algunos finales agudos, defecto de Arias Montano y no de fray Luis ni de su imitador, pudieran inducir a la creencia de que realmente pertenece esa oda al solitario de la Peńa de Aracena ${ }^{40}$.

A este juego de atribuciones en uno y otro sentido se presta el hecho de que fray Luis no publicara en vida sus poemas, que circularon de forma manuscrita hasta la primera edición a cargo de Quevedo en 1631. Esta larga trayectoria manuscrita explica, como escribe Menéndez Pelayo, que «unidas a las poesías auténticas de León corren otras muchas, apreciables casi todas, pero de origen más oscuro y controvertible... Ahora baste dejar sentado que, si no son de fray Luis, pertenecen a discípulos y admiradores suyos, es decir, a la escuela poética salmantina» ${ }^{41}$.

En cuanto a la atribución del poema «Del conocimiento de sí mismo» por el momento hay que barajar tres hipótesis:

IV.1 Primera hipótesis: si admitimos la autoría luisiana, estaríamos ante un caso evidente de interacción o imitación.

Los Hymni et Secula aparecieron en 1593, lo cual hace imposible que fray Luis, que murió en 1591, hubiera podido ver la obra publicada. Pero estos poemas circularon de forma manuscrita mucho tiempo antes de su publicación. Y por ello habría que calcular hacia qué fechas se compusieron los Hymni et Secula. La mejor información sobre este punto ${ }^{42}$ la ofrece

y el Cantar de los Cantares, Kassel, 2001, p. 51.

39. Merino, Obras del M. Fr. Luis de León, vol. VI, 115-119.

40. Francisco Cantera, «Arias Montano y Fray Luis de León», p. 301 demuestra, por su parte, que la oda debe mucho más a la Paráfrasis del poeta de Belmonte que a la de Montano, aunque admite que pueda ser de algún otro imitador de fray Luis.

41. M. Menéndez Pelayo, Bibliografía hispano-latina clásica (Madrid, 1951), VI, 307. Texto citado por Félix García, Obras completas castellanas de Fray Luis de León, 2 vols., Madrid, BAC, 1967, II, 822.

42. Por ejemplo, en el libro VI de los Siglos Arias dedica su poema titulado «De Iesu praeceptoris oportuna erga discipulos prouidentia» a Levino Torrencio, «episcopum Antuerpiensem». Torrencio fue nombrado obispo de Amberes a mediados de 1576 precisamente por recomendación de Montano, según se lee en dos cartas conservadas en Simancas, la primera del 17 de mayo y la segunda del 25 de julio de 1576. Así pues, el terminus ante quem non fue escrito el poema es el 25 de julio de 1576. Poco después se nombró obispo al humanista de Gante, y sería bastante plausible que Arias Montano compusiera por las mismas fechas que cierran el manuscrito 155 una oda que celebrara la dignidad recién obtenida por un ańorado amigo. 
el manuscrito 155 de la Biblioteca Nacional, que contiene gran parte de los poemas que aparecieron publicados en esa colección. A lo largo del manuscrito Montano anota tres fechas durante el proceso de composición ${ }^{43}$ : la primera de ellas «Romae [...] 1575»; la segunda, octubre de 1576; la tercera fecha, que pone fin al último poema del libro de los Himnos, es un poco posterior: Madrid, a 4 de noviembre de 1576. Podemos concluir, por tanto, que con mucha probabilidad Arias Montano compuso los tres poemas latinos que aquí estudiamos entre 1575 y 1576 . Y precisamente estos ańos coinciden de lleno con el período de producción poética de fray Luis.

IV.2 Segunda hipótesis: $\mathrm{Si}$, como argumenta parte de la crítica, el poema no es de fray Luis, debemos plantearnos si puede ahijarse a Arias Montano. Aparte de las conexiones ya probadas existen otros argumentos formales a favor de esta hipótesis: el primero es la conocida verbosidad montaniana. La mayor parte de sus poemas o bien roza o bien supera de forma amplia el centenar de versos. Como ejemplo, sólo la "Agnitio» tiene 90 versos; pero el «Votum Poenitentiae» está compuesto de 156 versos, y la «Paraenesis ad mentem propriam» de 228. La canción "Del conocimiento de sí mismo", con 169 versos, es, con mucho, la más larga de todos los poemas originales y atribuidos a fray Luis de León, quien sólo alcanza los 160 versos en su oda $\mathrm{XX}$ «A Santiago».

En cuanto a la métrica, fray Luis utiliza en sus poemas originales sobre todo la lira. Arias Montano en su Paráfrasis sobre el Cantar de los Cantares emplea mayoritariamente estancias de canción, y el tipo más abundante es el de 13 versos por estrofa, una nueva coincidencia con la canción «Del conocimiento de sí mismo» ${ }^{44}$. La canción petrarquista en vernáculo no presenta finales de

En la oda "Tempus omne Iesu laudibus impensum perpetuum iucundum et gratum fore», dedicada a Gabriel de Zayas, el poeta intenta persuadir al valido del rey de que toda edad es adecuada para componer poesía dedicada a Dios, dando comienzo a su oda con estas palabras: «iPreguntas, amable Zayas, si es oportuno que señores ancianos compongan versos, y te extrańas de que tu querido amigo de cabeza antes de tiempo canosa ("praecani") y de voz casi ("prope") temblona juegue con el plectro y los muelles versos?». En 1576, fecha en la que todas las referencias anteriores parecen situar la composición de Hymni et Secula, Montano tenía cincuenta años. Incluso a esa edad resulta forzado que alguien diga que tiene la cabeza canosa antes de tiempo, frase inadmisible en el caso de una persona de 63 ańos, edad que tenía Montano cuando se publicaron sus Hymni et Secula. Concluimos, pues, que esta referencia apunta a una composición temprana de la colección lírica montaniana.

43. Las referencias se pueden leer, respectivamente, en Biblioteca Nacional, Ms. 155, ff. $232^{\mathrm{v}}, 290^{\mathrm{r}}$ y $292^{\mathrm{v}}$.

44. Cf. L. Gómez Canseco - V. Núñez Rivera, Arias Montano y el Cantar de los Cantares, Kassel, 2001, p. 103-104. 
verso agudos, imperfección que sí está presente en la Paráfrasis al Cantar de los Cantares de Montano. Sin embargo, esta cuestión puede servir como referencia de datación, ya que Montano compuso su paráfrasis en época temprana, hacia los años cincuenta, cuando aún era inmadura la importación del endecasílabo a la lengua castellana. Hacia los años sesenta este tipo de cuestiones fue limándose. En mi opinión, si la canción «Del conocimiento de sí mismo" fuera obra de Arias Montano, tendríamos una prueba más para su datación tardía, hacia los años setenta, fecha precisamente de la composición de los tres poemas neolatinos destinados a los Hymni et secula.

IV.3 Tercera hipótesis: que la canción castellana sea obra de algún imitador de fray Luis y admirador de Arias Montano. En el propio círculo montaniano se movió un poeta que puede responder a estas características, su discípulo escurialense fray José de Sigüenza. Me parece, cuando menos, curioso que sea obra de Sigüenza la única copia manuscrita de dos de los poemas latinos aquí estudiados. Y que, además, realizara una traducción castellana del «Votum Poenitentiae» con imágenes y rimas calcadas de las poesías originales de fray Luis.

En esta traducción podemos leer los siguientes versos:

¿Quien me dará de los del sacro coro

Sean mis ojos dos eternas fuentes

De amargo lloro?

un terceto donde se recurre a una imagen petrarquista tan propia de fray Luis de los ojos como fuentes:

mis ojos, dos mortales

fraguas, dos fuentes sean manantiales

(oda VI, 79-80)

y que, al mismo tiempo, emplea la rima «sacro coro-lloro», calcada de otra oda luisiana:

A este bien os llamo,

gloria del apolíneo sacro coro,

amigos (a quien amo

sobre todo tesoro),

que todo lo visible es triste lloro.

(oda III, vv. 41-45) 


\section{Conclusión}

Cada una de las coincidencias por separado entre el poema atribuido a fray Luis y los poemas latinos de Arias Montano no es definitiva por sí misma más que para corroborar la idéntica formación y el mismo concepto de poesía de sus autores; pero el conjunto de estas coincidencias sí que demuestra una obvia interacción entre los versos latinos y los castellanos, e incluso no sería descabellado plantear la atribución de la canción «Del conocimiento de sí mismo» a Arias Montano o algún poeta de su círculo. Esta última cuestión tal vez sea insoluble y, por supuesto, sigue abierta. 